\title{
New approaches towards explaining construction methods of the great pyramid at Keops
}

\author{
İsmail Yilmaz ${ }^{1}$
}

\begin{abstract}
The importance of the Keops pyramid in terms of size and mass, has led to the proposal of three theories as to its modes of construction. The first theory argues that elephants and soldiers were employed for this work, which suggests considerable application of muscle power. The second states that the quarried stone blocks were transported to the pyramid construction site using elephants on a weight-bearing mechanism. The third suggests that stone blocks carried to the pyramid, were first uplifted with brute force, following which they were carried to the top, using the principle of buoyancy of water, through a system of graded pools. Theories suggested for the construction of this pyramid, can be applied to that of other pyramids. This paper analyses the construction of pyramids in terms of issues related to the quarry, stages of transport of stones from the quarry to the pyramid site and the final construction stage. Based on the theories explained in this study, the time period for the construction of the pyramid will be calculated, using expected values derived from the four different pool systems.
\end{abstract}

Keywords: Keops, pyramid construction, graded pool systems

\section{Introduction}

Amongst numerous pyramids constructed through the ages, the most well-known belong to the Egyptian civilisation. However, there are pyramids that may probably be attributed to the Turks, and there are those that require further research within the People's Republic of China. There are pyramids and pyramid-like constructions, which occur in different parts of the world. Except for the former two categories, the Keops pyramid in Egypt is the most important in terms of construction technology and engineering, owing to its dimensions and the size of the stone blocks used. The construction methods during this period required force, which was provided by physical strength. The limitations of the material, tools and force to uplift stone blocks, and the construction

\footnotetext{
1 Assoc. Prof. Dr., Sakarya University, Education Faculty, Elementary Education, Hendek, Sakarya, Turkey, iyilmaz@sakarya.edu.tr
} 

Journal of Human Sciences, 12(2), 8-20. doi: 10.14687/ijhs.v12i2.3228

technology and engineering used when muscle power was not enough, are factors applicable in the construction of other pyramids, as well.

Egyptians are known to have standardised their measurements and scales. They had the construction technology and engineering to manage and inspect the river Nile, and therefore they were able to deliver water needed for agriculture through channels to fertile land. For most of the time, they were able to produce abundant and high quality products. Along with agriculture, they raised cattle, mainly in the Nile delta. The Nile valley also served as a quarry, and the Egyptians were masters at stone cutting, as well as at metal working. Their success in construction was based on their practical experience and skills in construction engineering. The lumber required was obtained from their neighbours. In fact, Egyptians were a practical people, who focused on advantageous results, rather than on essential principles (Ronan, 1983, pp: 14-16; McClellan III \& Dorn, 1999, pp: 42). In this context, and as discussed later, they must have known of African elephants. Further, construction was possible only when the population was of a sufficient size. Although the date for the development of tyres (Hart-Davis, 2009, pp: 20-21), coincides with the period of construction of the Keops pyramid, it is not possible to state that tyres were used in the transportation of stone blocks.

This study proposes three theories for the construction of the Keops pyramid, taking into consideration, limitations of material and theoretical knowledge in ancient Egypt. One of these theories is based on their geographical position, construction technology and engineering skills used to manage and inspect water; the other two theories are related to methods for transporting stone blocks. Moreover, constructional analysis will be conducted by evaluating possible circumstances and through application of necessary calculations. Constructional technology and engineering theories that are established in the case of Keops, will be generalised to discuss similar pyramids elsewhere.

\section{Theories}

The following points are considered, in the context of construction of the pyramid:-

1. The stone blocks that were carried to the pyramid were uplifted until physical strength could no longer be effective. Following this, they were transported to the top of the pyramid, by using the principle of buoyancy of water, through a system of graded small pools.

2. For completing difficult work, muscle power was provided by elephants and by soldiers.

3. Stone blocks quarried were transported to the pyramid by using elephants over a weightbearing mechanism. 
Yilmaz, İ. (2015). New approaches towards explaining construction methods of the great pyramid at Keops. International Journal of Human Sciences, 12(2), 8-20. doi: 10.14687/ijhs.v12i2.3228

\section{Methods of Construction}

In constructing the pyramid, the principle of buoyancy of liquids may have been used when stone blocks were to be moved parallel to gravity. For other motion directions, physical force was used. Here, the techniques used, ensured the applicability of different methods. Construction technology and engineering comprised these methods and techniques. The construction of the pyramids can be examined in three ways:-1) study of the quarry from where stones were obtained;2) transportation of stone blocks from the quarry to the pyramid, and 3) the construction stage of the pyramids.

In this study the quarry phase will not be analysed. As the Keops pyramid rose in prominence in terms of size and mass, theories established for its construction will be used to explain the construction of pyramids as a whole. We accept the fact that average sized stone blocks were used in the construction. This enables one to standardise explanations of techniques used, and yet does not affect theories related to the methods of construction. Transportation methods and techniques were influenced by the size and mass of stone blocks. Construction methods and techniques determine the size of the pyramids and the size and mass of stone blocks used. Although the date for the development of the tyre coincides with the construction period of the Keops pyramid, there is no evidence that tyres were used in transporting stone blocks. Therefore different systems might have been developed to reduce friction during the movement of stone blocks. In this study, we suggest the use of an inclined mechanism, being one of the systems used to reduce friction. This might have been mainly built of lumber. Stone blocks could be moved by pushing, pulling or by buoyancy. It is proposed that in movement parallel to gravity, buoyancy was used, and in other directions of movement, pushing or pulling forces were applied. It is predicted that pushing and pulling movements were provided by the muscle power of elephants and soldiers. The direction of the pulling force could be changed. Ropes may have been used in order to transmit this force, and timber poles or elephant bones, could have been used to change the direction of motion. It is suggested that stone blocks were carried up to a certain level of the pyramid by sheer strength. In this study, we assume, for purposes of calculation, that this could be achieved up to a height of the tenth floor. It is assumed that the slope ratio of these tracks were lower than that of the pyramid.

After the last point to which stone blocks could be carried by muscle power, a graded pool system was introduced, which made use of buoyancy, in order to carry stone blocks over the pyramid. After reaching a certain height with the help of this pool, it was possible to be shifted to another pool via a base lid. A high density water mixture was used in these pools. In order to help lift stone blocks, we assume that a lever was employed. This would necessarily have been of a material with a lower density than the liquids used. The pool in which the stone blocks lay, could be filled with liquid from the next pool. In this study, we suggest that a combined pool system was used in order 
Yilmaz, İ. (2015). New approaches towards explaining construction methods of the great pyramid at Keops. International Journal of Human Sciences, 12(2), 8-20. doi: 10.14687/ijhs.v12i2.3228

to reduce the work load, which enabled automatic liquid transfers. People using buckets, possibly helped move remaining liquids which were not automatically transferred. The stone blocks lifted to the top of the pyramid using the principle of buoyancy, could be fitted in their places by people. In some types of pools, stone blocks could be put in place using gravity of levers. In this case, levers could be lowered onto each side of the pyramid. With the help of such levers, stone blocks could be put in place. In this study, we suggest that the transportation, lifting and stacking of pyramids is assumed to have been simultaneous; calculations were made using the values given in Table 1. In these calculations, either the transfer of the liquid in the pool, or the time used by people to transfer the liquid, had a time limitation. Data in Table 1 can be altered, with fresh calculations being possible. In this study, calculations are made for four different types of pools which have the same floor space. The pools are assumed to have been constructed at the mid-point of each side. Calculations are made assuming that each pool floor space equalled that of six stone blocks, and that four stone blocks were lifted to a height equalling that of three stone blocks through one pool. The total height of the pool may be determined based on the lever and stone block movement techniques. For movements in the pool, a shifting or floating technique was used. A lever is assumed to have been made of hollow lumber in the size of stone blocks. The balance of the levers is assumed to have been preserved, when the stone blocks were removed.

\section{Remarks}

Activities in the quarry could be divided into two categories. The first comprised cutting stones from the rocks, and the second involved lowering these stones from the quarry. Stone blocks were placed on an inclined ramp, using a pushing and/or pulling force. With the help of an inclined ramp which transferred the force and reduced its effects, stone blocks could be quickly transported to the pyramid by using a pulling force. The choice of force depended on advantages offered. The pulling force could be transferred by ropes. Ropes were made with threads, including those comprising leather and intestines. For the length of the inclined ramp, the pulling force provided by elephants and lumber, should be considered. Lumber used in the inclined ramp could be joined together with wooden fittings, metal or wooden nails or ropes. The technology and engineering required to cut stones from the rocks, could also limit the usage area of the pushing force. In this case, a pulling rather than a pushing force was used, as it had a more advantageous usage area. For instance, in narrow areas, the force needed could be applied as a pulling force by redirecting the rope.

In Ancient Egypt, elephants provided the greatest labour force. Therefore African elephants must have been used as the primary muscle power. The geographical context of the region, and their 
Yilmaz, İ. (2015). New approaches towards explaining construction methods of the great pyramid at Keops. International Journal of Human Sciences, 12(2), 8-20. doi: 10.14687/ijhs.v12i2.3228

knowledge of and skills with livestock, was proof that ancient Egyptians could feed and use elephants whenever a work force was needed. In comparison with other animals, the use of elephants was more efficient and thus become prominent. In transportation, elephants were more advantageous, because it was easier to control them. During this period, the force transition and efficiency of the tools used for pulling, were also advantageous for elephants. Further, feeding an elephant was 3 times more efficient than feeding an ox; although it was 4 times less efficient in terms of meat production. When an elephant needed to be slaughtered, its meat could be used for food and skin as isolation material or for ropes for the construction of the pyramid. Moreover, the remaining parts of the body could be used as clothing, as raw material for goods, or as a fertilizers, increasing their efficiency. In terms of muscle power, from a military point of view, elephants acted as a deterrent for enemies. Therefore, we may state that elephants were one of the main foundations for the continuation of the Ancient Egyptian Civilisation.

Though elephants are a part of the success story of a society interested in practical results, the second most important part of this story, comprise soldiers who constitute the other part of the muscle power. If the muscle power needed for the construction of the pyramids was acquired from slaves, it would imply the presence of an unproductive military force. To do so, would mean that we do not understand these people. This would hinder us from understanding the capability of sustaining a civilisation at a time when social order and wars were provided by muscle power, and when luxury could only accelerate its collapse. Soldiers did participate in work that required muscle power in the construction of the pyramid; they supported their civilisation efficiently here, in addition to that in the battle fields. They must have taken on the task of supporting society, and of being on guard against neighbouring societies, by continuing their physical development, through work which required muscle power. Slaves, on the other hand, must have served in daily work in order to support this muscle power. For instance, slaves must have been responsible for feeding the soldiers, elephants, etc. Therefore soldiers would be both ready for military work at any time, and would gain great technical knowledge and skills. So, elephants and soldiers became a productive force that was powerful and which supported this civilisation.

Stone blocks that were transported from the quarry by elephants, must have been carried by them via ramps which had a lower slope than that of the pyramid. The slope ratio could be determined by the material used in the ramps and the force of the elephants. In ramps towards the top of the pyramid, soil or sand was used as a packing material. In cases when the amount of the packing material, force of the elephants and time limitations, negatively affected the number of stone blocks that needed to be lifted, the power that moved the blocks could be shifted. At this point, buoyancy, which moved stone blocks parallel to gravity, could be used. Even if a civilisation lacked knowledge 
Yllmaz, İ. (2015). New approaches towards explaining construction methods of the great pyramid at Keops. International Journal of Human Sciences, 12(2), 8-20. doi: 10.14687/ijhs.v12i2.3228

of the main principles of buoyancy, they knew how to manage and inspect water; they were interested in advantageous results, and must have experienced the practical effects of this principle. Sailing ships are good evidence for this. Moreover, they must have developed a construction technology and engineering, necessary for pool construction, through their efforts at building barrages and channels for irrigation.

Stone blocks were lifted to the top of the pyramid through a staged pool system which was based on the principle of buoyancy of liquids. When stone blocks were lifted up to a certain level, they were moved to another pool. Water or a dense water mixture might have been used. In order to help lift stone blocks, another material which has a lower density than liquids might have been used as levers. Stone blocks could be transferred into a pool, through a lower lid, following which the lid was closed and the liquid transferred into upper, lower or side pools. Filling up the liquid was all about doing work in small sections. The system which had the most efficiency (time, number of workers, work efficiency) was a combined pool system, because almost half or more than half of the liquid was automatically transferred. This could have been achieved in the following manner:First the connection between the liquid in the upper pool and lower pool was stopped in order to transfer stone blocks to the upper pool. Then the liquid in the lower pool was automatically transferred.

Depending on the construction time, one or more pools could be built on each side of the pyramid. If more than one pool was built, excepting from one point in the same direction, and depending on the number of the stone blocks placed on top of the pyramid, the upper pool would require to be shifted to a point where they could be combined. One or more pools could be constructed at one point on the same side. At this point, the pools would require to be placed along the middle of that side. Pools could be single or combined, based on the construction engineering and technology available. The floor space, height and wall thickness of the pools, were related to:-a) the number of stones that had to be carried, b) the stones that were to be quarried, and c) the construction engineering and technology available. In this study, the construction of the pyramid is explained by applying the 'Double Combined Pool Method', by which pools were placed along the mid-point of each side of the pyramid. Through this method, the pools would have been able to lift four stone blocks up to the height of three stone blocks.

A graded pool was constructed by the side of the pyramid. In this system, the front wall of the upper pool began where the back wall of the lower pool ended. To achieve this, stone blocks were removed from the pyramid. The stone blocks removed from the pyramid were used to build the pools. The floor space of the pool and the height desired to be reached, determined the number of stone blocks to be removed. The floor space of the pool was determined by the number of blocks 
Yllmaz, I. (2015). New approaches towards explaining construction methods of the great pyramid at Keops. International Journal of Human Sciences, 12(2), 8-20. doi: 10.14687/ijhs.v12i2.3228

that were to be lifted. The base of the pool could be square or rectangular. The height of the pool was determined by the height desired to be reached, and by ways in which the blocks were to be moved. If the blocks were to be transferred by shifting them outside the liquid, the height of the pool was as much as the height that was to be reached. If the blocks were to be transferred to the upper pool by shifting within the liquid, the height of the pool was to exceed the height to be reached by the height of one stone block. In this case, the walls were to be at least two blocks thick, with removal of blocks in places where the new stone blocks were to be moved. While using levers, the heights of both pools were to be at least one-stone block higher than that of the blocks to be moved. If the stone blocks were to be transferred to the upper pool by floating, a liquid dense enough to float the blocks could not be used and a lever was needed. In this case, the height of the pool was to be two blocks higher than the height that was to be reached. In this study, the height is accepted to have been a three-tone block height. The calculations are based on four different pool systems which have a six-stone floor space of combined pools. These four pool systems are as follows: 1) combined pools in which stone blocks were shifted in or outside the liquid, and 2) combined pools which had a single or double wall thickness in which stone blocks were floated. There were levers in all types of pools.

For a material to function as a lever in a liquid, its density had to be lower than that of the liquid used. This lever could be made by using a material which had a lower density than the liquid or by enlarging the volume of the material to reduce its density. The best results were when both were used together. For example, a hollow lever could be made of wood, which has a lower density than water. The floor space of the lever was to be as large as that of the blocks to be transported, and it's height as much as that of the blocks. It could be made in different sizes; however, in this case the pools had to be raised, and this would cause balance problems. The technique used to transfer stone blocks to the upper pool determined the lid system used. In order to transfer stone blocks to the upper pool, shifting or floating techniques could have been used. In both techniques, blocks were transferred to the upper pool either by a pulling or by a pushing force. This was particularly so in areas too constrained for people to work. In order to transfer the blocks, the pulling force could be redirected, avoiding problems caused by the shortage of suitable space affecting the work force. The place of the lids was dependent on the position of the upper pool. If the stone blocks were to be shifted to the upper pool, they could be transferred through the front or side lid. In the case of single pools, two lids on the sides could have been used. If a lever was used in this technique, the balance had to be preserved when the stone blocks were removed. When more than one stone block was placed on the lever, the balance could be preserved by removing them simultaneously. If 
Yllmaz, I. (2015). New approaches towards explaining construction methods of the great pyramid at Keops. International Journal of Human Sciences, 12(2), 8-20. doi: 10.14687/ijhs.v12i2.3228

the stone blocks were to be floated, the lever had to be transferred through the front lid along with the stone block. The combined pools were connected to each other through a lid on the floor.

In this study, we suggest that, in the two types of pools in which the floating technique was used, levers which were uplifted along with stone blocks could be used to place the blocks on top of the pyramid. This possibility removed the difficulty for working on a surface area which reduced as the height of the pyramid increased. The stone blocks tied to the levers could be moved by shifting the levers down, along the sides of the pyramid. Stone blocks could be placed in desired places by shifting levers from different sides. This technique used to place the stone blocks, enabled synchronization between two different types of work. It ensured that stone blocks were placed at the same time, and also minimised the number of workers required to work on the pyramid. This technique reduced both the duration of construction of the pyramid and the number of workers required.

The average density of limestone used is assumed to be $2500 \mathrm{~kg} / \mathrm{m}^{3}$ and mass to be $2500 \mathrm{~kg}$; and the stone block was square with dimensions of $1 \mathrm{~m}$ along each side (width, length, height). If the width and length of the pyramid was around $230 \mathrm{~m}$ then around $52900(230 * 230)$ stone blocks were placed on the floor. The slope ratio was half that of the length/height and equalled 0.787671233(Golden Ratio). Therefore, the second line of 52177.82 stone blocks were placed with a stone blocks decrease of 722.17 . For the next line, the same slope ratio was preserved and with a 4.96 majority increase in stone blocks placed. Therefore on line 146, 2.48 stone blocks were placed and the pyramid was completed with $26,00,977$ stone blocks. The use of muscle power would thus place 497097.7 stone blocks up to and including line 10. Therefore, one-fifth of the pyramid could be completed by transporting stone blocks using muscle power. In this calculation, the tenth line of the pyramid could be completed on the $497^{\text {th }}$ day, assuming that 1000 stone blocks were carried per day. We suggest that four-fifth of the blocks were carried up to the pyramid via pools from the $10^{\text {th }}$ line onwards. To model the construction of the pyramid, data in Table 1 was used and calculations made according to the four different types of pools are given in Tables 2a,b,c and $d$. Synchronization and time limitations are factored into the calculations. These time limitations were applied for issues related to work completed, transfer of liquids or transfer of liquids by individuals. Results of the calculations based on these limitations are summarised as follows:

If the stone blocks were shifted outside the pool (Table 2, column 2), around 64 to 72 stone blocks could be lifted daily making a total of $21,03,879$ stone blocks over 80.1 to 90.1 years. If the duration spent to complete the first 10 lines are added to this time frame, the pyramid could be completed in 81.4 to 91.4 years. 

Journal of Human Sciences, 12(2), 8-20. doi: 10.14687/ijhs.v12i2.3228

If the stone blocks were shifted in the pool (Table 2, column 3), around 114 to 123 stone blocks could be lifted daily and this makes a total of $21,03,879$ stone blocks, and 46.8 to 50.3 years. The pyramid could be constructed in 48.1 to 51.7 years.

If stone blocks were floated in double-walled pools (Table 2, column 4), around 254 to 279 stone blocks of them could be lifted daily; this makes a total of 21,03,879 stone blocks and 20.6 to 22.6 years. The pyramid could be completed in 21.9 to 23.9 years.

If stone blocks were floated in single-walled pools (Table 2, column 5), around 266 to 293 of them could be lifted daily; this makes a total of $21,03,879$ stone blocks over 19.6 to 21.6 years. The pyramid could be completed in 20.9 to 22.9 years.

\section{Results and Comments}

The nature of a civilisation to focus on practical and advantageous results may also help them learn to work on techniques separated into small pieces. With this knowledge, they might have used water management techniques on graded pool systems, and adopted this to build the pyramids. The pool examples cited above, or other pool systems, might have been used. The type of pool system used was related to the relationship between practicality and knowledge. As these people were interested in practical results, it is possible that they might have used the floating technique which had practical results. It is only possible to understand which pool system was used, after analysis of the stone blocks utilised for the pyramid. If the Keops pyramid was built using the graded pool system, making use of buoyancy, the least troublesome would be the construction area. This is seen when the results in Table 2 are evaluated based on the data in Table 1, as it would require the least amount of muscle power (animals and people) in construction. Moreover, if there were times when muscle power was insufficient to quarry stones, they might have used these methods and techniques to lift stone blocks to the pyramid.

Following these suggestions, we now need to explain the duration of the construction of the Keops pyramid, factors affecting construction stages, and methods and techniques suitable to speed up quarrying. The construction technology and engineering used in the Keops pyramid might have been used for the construction of other pyramids. Every civilisation located near sources of water, must have experienced these practical results, even though they may not have known the essential principles of buoyancy. In order to prove that water craft were used, ships, boats, etc. can be studied. Common experiences might stimulate similar results. The continuity of civilisations was affected by how they applied their muscle power. Wrong choices would cause the civilisations to collapse. 
It is worth explaining why information on the construction of one of the seven wonders of antiquity, the Keops pyramid, has not survived. This is more so, as in Ancient Egypt, important events were inscribed on stones, with the knowledge of papyrus seen well before the construction of the pyramid (Ronan, 1983, pp: 15). Thus, there is a low probability that such a civilisation did not record this information. A further question is why six of the seven ancient wonders have not survived. The answers to these questions help us understand important historical events and governance which were responsible for these wonders. History consists of these treasures, as well as the need to preserve them.

\section{Reference}

Hart-Davis, A. (2008). Science, DK (Çeviri: Ünlü, B. (2012). Bilim atlası, Boyut Yayınc1lık, İstanbul, ss: 20-21.)

Mc Clellan III, J. E. ve Dorn, H. (1999). Science and technology in world history, The Johns Hopkins University Press (Çeviri: Yalçın, H. (2006). Dünya tarihinde bilim ve teknoloji, Arkadaş yayınevi, Ankara, s: 42.)

Ronan, C. A. (1983). Science: Its history and development among world culrutes (Çeviri: İhsanoğlu, E. ve Günergun F. (2003). Bilim tarihi: Dünya kültürlerinde bilimin tarihi ve gelişimi, TÜBİTAK Yayınları, Ankara, 14-16.) 
Yllmaz, İ. (2015). New approaches towards explaining construction methods of the great pyramid at Keops. International Journal of Human Sciences, 12(2), 8-20. doi: 10.14687/ijhs.v12i2.3228

Table1: Values provided for the construction of the pyramid

\begin{tabular}{|c|c|}
\hline Liquid transfer duration in single line pool(hour) & 0.5 \\
\hline Liquid transfer duration in double line pool (hour) & 0.5 \\
\hline Liquid transfer duration in double line pool with front lid (hour) & 0.5 \\
\hline Liquid transfer duration in single line pool with front lid (hour) & 0.5 \\
\hline Stone shifting duration in single line pool (hour) & 2 \\
\hline Stone shifting duration in double line pool (hour) & 0.8 \\
\hline Stone shifting duration in double line pool with front lid (hour) & 0.1 \\
\hline Stone shifting duration in single line pool with front lid (hour) & 0.1 \\
\hline Daily shift duration & 10 \\
\hline Annual shift (number of days) & 365 \\
\hline Number of stones transported daily & 1000 \\
\hline Number of stones uplifted by carrying & 10 \\
\hline Direction of the rise and the number of pools & 4 \\
\hline Number of combined pools & 2 \\
\hline Number of quarrying & 4 \\
\hline Shift of transportation & 2 \\
\hline Shift of pyramid & 2 \\
\hline Density of the liquid & 1.1 \\
\hline Number of workers stacking stones and working & 200 \\
\hline Total Number of workers working in the pool & 30 \\
\hline Number of workers shifting stones in the pool & 20 \\
\hline Number of workers transferring liquid in the pool & 30 \\
\hline Amount of liquid that one person can transfer at once $\left(\mathrm{m}^{3}\right)$ & 0.02 \\
\hline A worker's duration of transferring one bucket of liquid (minute) & 1 \\
\hline Amount of liquid automatically transferred & 0.5 \\
\hline Number of stone blocks removed from the width & 2 \\
\hline Number of stone blocks removed from the height & 3 \\
\hline Height of the rise of a stone block in one pool & 3 \\
\hline Density of stone block " $\mathrm{g} / \mathrm{cm}^{3 "}$ & 2.5 \\
\hline Density of lever $\mathrm{g} / \mathrm{cm}^{3} "$ & 0.5 \\
\hline Mass of lever "ton" & 1 \\
\hline Momentum of gravity "m/s" & 9.8 \\
\hline $\mathrm{y}$ value for the angle of stone block(m) & 0.79 \\
\hline $\mathrm{h}$ value for the angle of stone block $(\mathrm{m})$ & 1 \\
\hline $\mathrm{y}$ value for the angle of lever(m) & 0.79 \\
\hline $\mathrm{h}$ value for the angle of lever(m) & 1 \\
\hline Width of the pyramid(x; m) & 230 \\
\hline Height of the pyramid(y; m) & 230 \\
\hline Height of the pyramid(h; m) & 146 \\
\hline Width of the stone blocks(x; m) & 1 \\
\hline Height of the stone blocks $(y ; m)$ & 1 \\
\hline Height of the stone blocks(h; m) & 1 \\
\hline Width of the lever(x; m) & 2 \\
\hline Height of the lever $(y ; m)$ & 2 \\
\hline Height of the lever(h; m) & 1 \\
\hline
\end{tabular}


Yllmaz, İ. (2015). New approaches towards explaining construction methods of the great pyramid at Keops. International Journal of Human Sciences, 12(2), 8-20. doi: 10.14687/ijhs.v12i2.3228

Table 2a: Results of calculations for adding water or transferring water with time limitations based on values given for the construction of the pyramid

\begin{tabular}{|c|c|c|c|c|}
\hline & 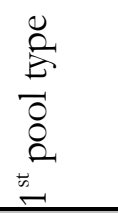 & 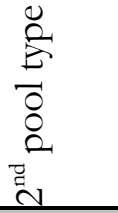 & 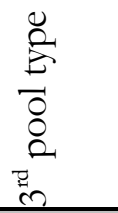 & 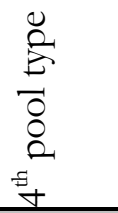 \\
\hline Duration of uplifting stones (hour) & 2.5 & 1.3 & 0.6 & 0.6 \\
\hline Duration of liquid transfer (hour) & 0.5 & 0.5 & 0.5 & 0.5 \\
\hline Duration of shifting stone in pool (hour) & 2.0 & 0.8 & 0.1 & 0.1 \\
\hline Total number of stones uplifted (day) & 64.0 & 123.1 & 266.7 & 266.7 \\
\hline Total number of stones uplifted (year) & 23360.0 & 44923.1 & 97333.3 & 97333.3 \\
\hline Construction time (via pool, year) & 90.1 & 46.8 & 21.6 & 21.6 \\
\hline Construction time (Total, year) & 91.4 & 48.2 & 22.9 & 22.9 \\
\hline $\begin{array}{l}\text { Volume of the liquid overflow in adding } \\
\text { above }\left(\mathrm{m}^{3}\right)\end{array}$ & 8 & 19.5 & 17 & 16 \\
\hline
\end{tabular}

Table 2b: Results of the calculations for adding water with time limitations based on values given for the construction of the pyramid

\begin{tabular}{|c|c|c|c|c|}
\hline & 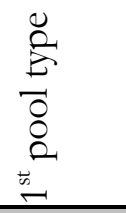 & 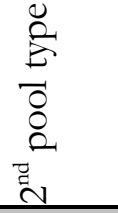 & 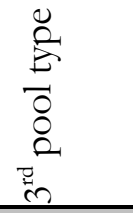 & 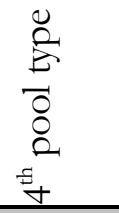 \\
\hline Duration of uplifting stones (hour) & 2.5 & 1.3 & 0.6 & 0.6 \\
\hline Duration of liquid transfer (hour) & 0.5 & 0.5 & 0.5 & 0.5 \\
\hline Duration of shifting stone in pool (hour) & 2.0 & 0.8 & 0.1 & 0.1 \\
\hline Total number of stones uplifted (day) & 64.0 & 123.1 & 266.7 & 266.7 \\
\hline Total number of stones uplifted (year) & 23360.0 & 44923.1 & 97333.3 & 97333.3 \\
\hline Construction time (via pool. year) & 90.1 & 46.8 & 21.6 & 21.6 \\
\hline Construction time (Total. year) & 91.4 & 48.2 & 22.9 & 22.9 \\
\hline $\begin{array}{l}\text { Volume of the liquid overflow in adding } \\
\text { above }\left(\mathrm{m}^{3}\right)\end{array}$ & 8 & 21.5 & 19 & 18 \\
\hline
\end{tabular}



Journal of Human Sciences, 12(2), 8-20. doi: 10.14687/ijhs.v12i2.3228

Table 2c: This provides results of the calculations for adding water and for shifting stone blocks with time limitations based on values given for the construction of the pyramid

\begin{tabular}{|c|c|c|c|c|}
\hline & 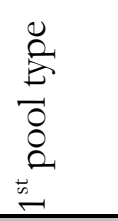 & 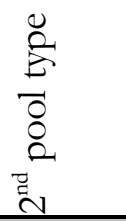 & 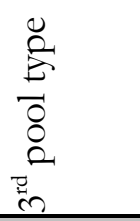 & 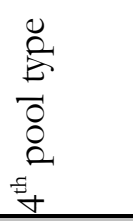 \\
\hline Duration of uplifting stones (hour) & 2.2 & 1.3 & 0.6 & 0.5 \\
\hline Duration of liquid transfer (hour) & 0.2 & 0.5 & 0.5 & 0.4 \\
\hline Duration of shifting stone in pool (hour) & 2.0 & 0.8 & 0.1 & 0.1 \\
\hline Total number of stones uplifted (day) & 72.0 & 119.3 & 279.6 & 293.9 \\
\hline Total number of stones uplifted (year) & 26280.0 & 43528.0 & 102058.3 & 107265.3 \\
\hline Construction time (via pool. year) & 80.1 & 48.3 & 20.6 & 19.6 \\
\hline Construction time (Total. year) & 81.4 & 49.7 & 21.9 & 20.9 \\
\hline $\begin{array}{l}\text { Volume of the liquid overflow in adding } \\
\text { above }\left(\mathrm{m}^{3}\right)\end{array}$ & 8 & 19.5 & 17 & 16 \\
\hline
\end{tabular}

Table 2d: This shows results of the calculations for lifting stone blocks. with time limitations based on values given for the construction of the pyramid

\begin{tabular}{|c|c|c|c|c|}
\hline & 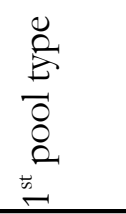 & 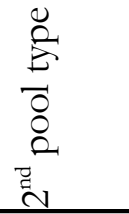 & 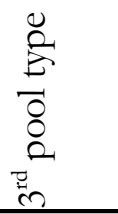 & 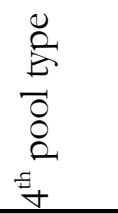 \\
\hline Duration of uplifting stones (hour) & 2.2 & 1.4 & 0.6 & 0.6 \\
\hline Duration of liquid transfer (hour) & 0.2 & 0.6 & 0.5 & 0.5 \\
\hline Duration of shifting stone in pool (hour) & 2.0 & 0.8 & 0.1 & 0.1 \\
\hline Total number of stones uplifted (day) & 72.0 & 114.5 & 254.9 & 266.7 \\
\hline Total number of stones uplifted (year) & 26280.0 & 41797.2 & 93026.5 & 97333.3 \\
\hline Construction time (via pool. year) & 80.1 & 50.3 & 22.6 & 21.6 \\
\hline Construction time (Total. year) & 81.4 & 51.7 & 23.9 & 22.9 \\
\hline $\begin{array}{l}\text { Volume of the liquid overflow in adding } \\
\text { the above }\left(\mathrm{m}^{3}\right)\end{array}$ & 8 & 21.5 & 19 & 18 \\
\hline
\end{tabular}

